\title{
DIÁLOGO CRÍTICO DE NIETZSCHE CON PLATÓN
}

Nietzsche's Critical Discussion with Plato

Enrico Müller

Universidad de Greifswald

Resumen: Nietzsche caracteriza su propio pensamiento como la «transformación de lo dionisíaco en un pathos filosófico» (Ecce Homo, «El nacimiento de la tragedia»). El concepto de pathos está dirigido contra la metafísica europea, que se presenta a sí misma como una filosofía del logos desde su fundación con Sócrates y Platón. La confrontación de Nietzsche con los dos atenienses, a lo largo de toda su vida, es un intento de transvalorar los valores filosóficos establecidos en los escritos de Platón bajo las condiciones de la Modernidad. Sin embargo, en este proyecto, Nietzsche descubre progresivamente a los individuos concretos detrás de la filosofía del logos: Sócrates más allá del socratismo y Platón más allá del platonismo.

Palabras claves: logos - transvaloración - metafísica

ABSTRACT: Nietzsche characterizes his own thinking as the «transformation of the Dionysiac into a philosophical pathos» (Ecce homo, "Birth of Tragedy»). Pathos is taken as a counter-concept against European metaphysics, presenting itself as a philosophy of the logos since its foundation by Socrates and Plato. Nietzsche's life-long altercation with the two Athenians is the attempt to revalue the philosophical values established in Plato's writings under the conditions of Modernity. In this project, however, Nietzsche discovers more and more the individuals beyond the philosophy of the logos: Socrates beyond 'Socratism' and Plato beyond 'Platonism'.

Keywords: logos - Revaluation - Metaphysics

El periodo de finales del siglo v y del siglo IV a.C. se puede concebir como una época en la que el acceso al mundo se fundaba en el logos. En esta época se crea y desarrolla un concepto tanto de la filosofía como de la ciencia que perdurará a lo largo de toda la historia de las ideas europea y que aún determina de forma decisiva el pensamiento actual. El logos, como discurso dirigido por la razón, aparece en el marco del origen del campo de la filosofía -que se inicia con Sócrates, Platón y Aristóteles- en calidad de autoridad que se pregunta acerca de la unidad que subyace a la diversidad y mutabilidad de los fenómenos del mundo de la vida. Platón, en el libro VII de La República, deja que su protagonista, Sócrates, caracterice de manera enfática esta nueva orientación del pensamiento como la entrada a una nueva vida: «la vuelta (metastrofe)» del pensamiento «desde el devenir a la verdad y al ser» sería una «liberación (lysis) de las cadenas», 
al mismo tiempo que una «vuelta desde las sombras a las formas y a la luz y una ascensión desde el abismo subterráneo hasta el sol» ${ }^{1}$.

La filosofía de Nietzsche como crítica a la metafísica empieza en este punto. Como es sabido, su filosofía estaba orientada en contra del rasgo centralizador de la razón, y así, en contra de su carácter normativo, universal e instrumental. Es más, la razón en sí, como se dice de forma aguda en El crepúsculo de los ídolos, no sería más que un prejuicio fundamental de los filósofos². Un filósofo de verdad y un «espíritu libre» debería según Nietzsche, bajo las condiciones de la modernidad, emanciparse también de la razón. Pero a la vez es cierto que el filosofar de los modernos y el de Nietzsche, permanece como pensamiento conceptual en un espacio demarcado y ampliamente delimitado por los griegos. La génesis de los conceptos, el descubrimiento de la razón misma, si se quiere, permanece como el logro único de una experiencia que ya no puede ser de nuevo inaugurada. Las distinciones filosóficas fundamentales de los griegos fueron decisiones. Como decisiones, sin embargo, se pudieron haber tomado de esta o de otra forma. Los griegos aún tuvieron elección, nosotros ya no la tenemos. De esa consciencia acerca del irrepetible carácter inicial de un primer acceso teórico es de la que se alimentan tanto la admiración de Nietzsche como su agresividad respecto a los filósofos griegos. Su trato crítico con la filosofía del logos adopta la forma de una discusión con los protagonistas de dicha filosofía, dilatada a lo largo de toda su vida. Su relación con Sócrates y Platón, que oscila entre la fascinación y la demarcación, la expresó Nietzsche muy pronto con vistas a sus propias ambiciones filosóficas. En una famosa anotación de 1870/71 caracteriza su propio pensamiento, por vía negativa, como un "platonismo invertido» ${ }^{3}$. Y en una confesión también famosa del año 1875 dice: «Sócrates, he de confesarlo, me es tan cercano, que casi siempre estoy en lucha con él» ${ }^{4}$.

Ambas citas nos llevan a la discusión sobre la relación de Nietzsche con sus antecesores de la Antigüedad. En estas citas queda claro que esta relación no se puede establecer, ni se puede criticar o valorar planteando el tema como algo cerrado. Pues a menudo los ataques más fuertes de Nietzsche se explican precisamente en función del grado de cercanía con respecto al objeto de dicho ataque: cuanto mayor sea esa cercanía, mayor es la agudeza de su juicio y más necesita separarse de su objeto. En esa lucha por delimitar las inabarcables similitudes, parece que Nietzsche repite a Sócrates y a Platón, pero lo hace como un filósofo que está ya bajo las condiciones de la Modernidad. Es válido interpretar sus disparates, sus ocasionales observaciones y explicaciones partiendo de perspectivas contrarias, como fases de una lucha, la cual — como «casi siempre»

1. Platón, República, VII, $525 \mathrm{c}$.

2. Véase El crepúsculo de los ídolos (GD), «La 'Razón’ en la filosofía». Con respecto al concepto nietzscheano de «razón» y su discusión con la filosofía tradicional de la conciencia, véase Erwin Schlimgen, Nietzsches Theorie des Bewusstseins, Berlín: W. de Gruyter, 1988, y últimamente, del autor de este artículo: «Stichwort: Vernunft», en Christian Niemeyer (ed.), Nietzsche-Lexicon, Darmstadt, 2009.

3. La formulación acentuada perteneciente a los fragmentos póstumos tempranos es suficientemente conocida, aquí añadimos el contexto: «Mi filosofía es un platonismo invertido: cuanto más lejos se está del ente verdadero, tanto más pura, bella y mejor es la vida. La vida en la apariencia como meta», FP I 185, 7[156].

4. FP II 105, 6[3]. 
defiende- no conoce ganadores ni perdedores definitivos. En cuanto al posicionamiento predominantemente polémico de Nietzsche frente a Sócrates y Platón es oportuno distinguir entre una macroperspectiva crítica con la metafísica y una microperspectiva ${ }^{5}$ genealógica. Con las nociones de «platonismo» $\mathrm{y}$ «socratismo» Nietzsche siempre critica un determinado sistema de diferencias metafísicas reguladoras. La crítica a las personalidades de Platón y Sócrates se realiza, sin embargo, en forma de una reconstrucción provocativa de las condiciones culturales e individuales, desde las cuales parten sus pensamientos. El cambio desde la macroperspectiva crítica con la metafísica a la microperspectiva genealógica permite que vuelvan a primer plano la fuerza explosiva histórica, la fuerza individual y la relevancia filosófica de la potencia del pensamiento de Sócrates y Platón. Estos se convierten en un problema real para Nietzsche, no como maestros de una determinada posición teórica, sino como individuos que filosofan.

El paralelismo nietzscheano entre el platonismo y la metafísica está formulado casi siempre como un enfrentamiento con Platón ${ }^{6}$. La figura de una inversión del platonismo ${ }^{7}$ tiene al menos dos caracteres: la inversión de la posición de Platón, o bien, la vuelta al platonismo a efectos de un nuevo enfrentamiento con él ${ }^{8}$. Inicialmente la conexión problemática entre Platón y el platonismo es el resultado de la historia concreta de su recepción: poco tiempo después de la muerte de Platón se extrajo de los Diálogos una parte supuestamente teórica, se compilaron, elevaron a doctrinas platónicas (dogmata) y fueron transmitidas, enseñadas y estudiadas como tales, por parte de las generaciones académicas sucesivas, como Aristóteles, quien califica los diálogos platónicos como (Sokratikoi $\operatorname{logoi})^{9}$, y como los filósofos de la escuela helenística. Hasta llegar a esta forma condensada de su doctrina, el autor no se convirtió finalmente en un objeto de

5. Con respecto a la genealogía como método crítico y estrategia retórica, cf. Michael Saar, Genealogie als Kritik, Frankfurt a. M., 2007.

6. Reinhardt Klemens Maurer, «Das antiplatonische Experiment Nietzsches. Zum Problem einer konsequenten Ideologiekritik»: Nietzsche-Studien 8 (1979), 104-126, lee la crítica nietzscheana al platonismo exclusivamente como crítica a la ideología de Platón. Esto le obliga a estrechar tanto el enfoque platónico como el nietzscheano, a saber, a la antinomia entre una teoría de la ideas ontológico-epistemológica y una radical teoría del conocimiento perspectivista. El «platonismo invertido» de Nietzsche fracasó entonces en esto, en que solamente era un experimento radical llevado a cabo por la vía de la negación, con respecto al cual Maurer plantea la siguiente pregunta: «si la exigencia positiva de futuro de la filosofía práctica de Nietzsche, el requerimiento de instaurar nuevos valores, concuerda con el relativismo y escepticismo total de su filosofía teórica» (p. 123). Más próximo a las fuentes argumenta Dieter Bremer, «Platonisches, Antiplatonisches. Aspekte der Plato-Rezeption in Nietzsches Versuch einer Wiederherstellung des frühgriechischen Daseinsvertändnisses»: NietzscheStudien 8 (1979), 39-103, quien visualiza la ambivalencia de las referencias platónicas en Nietzsche. La superación más extensa hasta ahora la ofrece Francesco Ghedini, Il Platone di Nietzsche. Genesi e motivi di un simbolo controverso (1846-1879), Napoli, 1999, quien debido a su limitación cronológica no puede reconstruir la imagen nietzscheana de Platón a partir del desarrollo de su filosofía.

7. También Victorino Tejera, Nietzsche and Greek Thought, entiende la crítica nietzscheana al platonismo en general como una crítica a Platón: «Así, si el lector, que considera la obra de Platón en su brillantez ingeniosa, alusiva y creativa, sustituyera 'Platón' por 'platonismo' cada vez que Nietzsche lo escribe quejándose, sería capaz de comprender en este punto un criticismo cultural válido. El aspecto filosófico de este criticismo es, para Nietzsche, el efecto distorsionado de la doctrina del idealismo en el pensamiento y en la práctica de Occidente» (p. 89).

8. Por este pensamiento abogó en última instancia Annamaria Lossi, Nietzsche und Plato: Begegnung auf dem Weg der Umdrehung des Platonismus, Würzburg, 2006.

9. Aristóteles, De Arte Poetica 47b. 
estudio disponible y canónico. Ya al inicio de la recepción del platonismo parece desaparecer Platón tras las posiciones del platonismo.

Comenzando por sus primeros escritos, Nietzsche ha entendido la obra de Platón en último término, y sobre todo, como el primer gran logro de sistematización y síntesis de los mundos tan dispares representados por los esquemas de pensamiento griego. Así aparece Platón en La filosofía en la época trágica de los griegos en contraste con los primeros pensadores griegos simplistas e individualistas como «el primer gran mestizo ${ }^{10}$. Se acentúa doblemente la gran tarea, personificada en Platón, de encontrar una relación entre los proyectos pitagóricos, parmenídeos y heraclíteos. Por un lado, como distanciamiento de los pensadores primeros permanece dicha tarea dirigida en el ámbito de las propias preguntas a los prominentes antecesores. Y por otro lado, en la medida en que los primeros filósofos griegos no son tratados en el corpus platonicum en forma de proyectos individuales, sino que se encuentran presentes en su mayoría como maestros de una determinada dirección filosófica supra-individual (überindividuell). En este sentido Nietzsche ha escogido el otro camino y se ha alejado de los esfuerzos platónico-aristotélicos de reconstrucción. Por otro lado, estuvo notablemente impresionado, hasta en su obra tardía, por cómo y de qué forma Platón llegó a compactar toda la «polifonía» del cosmos presocrático en un lenguaje filosófico cerrado en sí mismo. En el acto de esta mediación dialógica artística se estableció y diferenció el repertorio de conceptos sin los cuales no se podría pensar en una filosofía europea. Platón ha producido en Europa el mismo efecto como filósofo que como artista. Realmente siempre ha actuado a la vez como artista y como filósofo, sin que se tematizara la interacción entre la forma estética y el contenido proposicional de su propio proceso de recepción.

La problemática «Platón versus platonismo» destaca sobre el plano extrínseco de las etapas de recepción tradicionales ${ }^{11}$, se establece ya en la misma estructura del diálogo. Si se contempla la «dialogicidad» como característica constitutiva del filosofar platónico, resulta que cualquier forma de recepción, ya esté inspirada en las grandes «teorías» de los diálogos o proceda del aspecto dialógico-comunicativo-teorético, permanece siendo platonismo. Parece de hecho casi imposible una filosofía fuera del marco definido por Platón.

Nietzsche no vio con claridad la estructura paradójica de la obra platónica hasta su obra tardía, sin embargo no corrigió principalmente sus valoraciones excesivas y sus reservas generales. Sus reflexiones antiplatónicas se consolidarán aun más con la publicación de su obra tardía. Parece estar demasiado envuelto en si mismo, en aquella «lucha contra Platón", que "creó en Europa una maravillosa tensión de espíritu» ${ }^{12}$. Lo que ha desencadenado en el pensamiento de

10. PHG, en Obras completas, vol. 6, Buenos Aires: Aguilar, 1967, p. 202.

11. Carl August Emge, Der «umgedrehte Platonismus». Anregungen Nietzsches zur Situationphilosophie, Wiesbaden, 1952, no le hace justicia al título exigente de su obra. El «platonismo invertido" de Nietzsche se interpreta y rechaza exclusivamente como "pensamiento de un 'giro' simplista» ( (Gedanken einer einseitigen 'Umdrehung'», p. 52).

12. JGB, prólogo, KSA V 12. Reiner Wiehl, «Nietzsches Anti-Platonismus», en J.-F. Courtine y R. Brague, Herméneutique et ontologie: mélanges en hommage à Pierre Aubenque, Paris: PUF, 1990, pp. 275-296, no quiere ver reducido, con razón, el antiplatonismo de Nietzsche a una mera crítica científica al supuesto «realismo conceptual» de Platón. Según Wiehl, el platonismo para Nietzsche es 
Platón esa «tensión» más allá de meros contraproyectos, se puede demostrar precisamente a partir de aquel Nietzsche que retrocede en el alejamiento demostrativo desde un determinado contenido dogmático-sistemático de la tradición a la vez que desde el platonismo y así redescubre parcialmente otro Platón. El "platonismo invertido» de Nietzsche tiene, en último término, rasgos platónicos irreconocibles ${ }^{13}$.

\section{AGRAFÍA, ANONIMATO, DIALOGICIDAD: INTERPRETACIÓN NIETZSCHEANA DE LA RELACIÓN PLATÓNICO-SOCRÁTICA}

Nietzsche —en contra de ciertas constataciones declaradas ${ }^{14}$ — ha tenido que considerar la paradoja de que el escritor de mayor impacto en occidente renunció a hablar en su propio nombre. Sócrates no escribió. Platón tuvo que escribir para conservar a Sócrates como filósofo. Pero también él dudó de la escritura, que en pasajes centrales de su obra somete a una crítica fundamental ${ }^{15}$. Que Platón prefiera, frente a una presentación monográfica, dejar hablar a determinadas personas entre sí, indica un concepto de la filosofía en el que se cuestiona la relación entre la objetividad y la individualidad. El anonimato del pensador con res-

un modo cultural y vital de Europa, una forma de la realidad europea en sí, a la que él creía no sólo criticar, sino que tenía que combatir hasta el final (p. 278).

13. Hay aquí mucho que naturalmente depende de la pregunta de hasta qué punto se entiende la explicación antiplatónica de la filosofía de Nietzsche como una ultima ratio de su concepto de filosofía. Si se hace esto, entonces la objeción de Bremer, platónico, antiplatónico (p. 65), está autorizada: «Se pregunta si y cómo una filosofía que se entiende como inversión del platonismo accede más allá de aquello que invierte». Stanley Rosen, «Nietzsches Platonismus»: Allgemeine Zeitschrift für Philosophie 12/2 (1987), 1-15, desplaza particularmente a Nietzsche y Platón del horizonte interpretativo ontológico demasiado estrecho de Heidegger. El punto de partida es también aquí el recurso a las prácticas literarias y sus implicaciones filosóficas. Rosen — quien en este aspecto opera de forma demasiado poco específica con el término "retórica»— ve en esto la unión de Nietzsche y Platón frente a Heidegger: para él se trata de «una parte constitutiva de la teoría tanto de Nietzsche como de Platón, pues esta teoría debe ser interpretada desde una retórica complicada. La importancia de la retórica es, en ambos casos, una consecuencia directa de la imposibilidad de la ontología» (p. 1).

14. Sorprendentemente Jacques Derrida también presupone, Die Postkarte von Sokrates bis Freud und jenseits. 1. Lieferung, Berlin, 1982 (Paris, 1980), p. 28, que Nietzsche, con respecto al problema fundamental de la imputación asociado con Platón y Sócrates, no había «comprendido nada de la catástrofe inicial». Ante el trasfondo del conocimiento profundo nietzscheano de Derrida, la siguiente declaración válida de Nietzsche casi no se deja explicar: «El creyó como todo el mundo que Sócrates no escribió, que venía de Platón, quien más o menos escribía bajo su dictado y a quien le dejaba escribir completamente solo [...]». Derrida generaliza aquí un aspecto aislado de las variadas reflexiones nietzscheanas para, en lo que sigue, revivir múltiples opciones, que ya se encuentran en Nietzsche. Victorino Tejera, Nietzsche and Greek Thought, cit., p. 86, constata seguramente de forma correcta: "Nietzsche, we see, has not clarified for himself the relations between dialogue-form and 'dialectic'» («Nietzsche, como vemos, no ha clarificado para sí la relación entre la forma dialógica y la 'dialéctica'»). Al margen de la pregunta de hasta qué punto es posible y razonable aclarar esta relación, ese diagnóstico ¿̇sólo es válido? para la mayoría de las manifestaciones nietzscheanas. En lo que sigue se discutirán cada vez más las excepciones ¿̇y contendrán una interpretación?.

15. Los trabajos sobre la crítica de la escritura en Fedro son muchos. Que aquí no subyace ninguna «oposición performativa» y que a su vez tampoco está cerca de una ciencia basada en principios orientada hacia una comunicación oral en exclusiva, es lo que muestra de forma convincente Wieland, Platon und die Formen des Wissens, Göttingen, 1982, pp. 13-38. 
pecto a sus escritos, que se rompe en quizás dos lugares del corpus platónico ${ }^{16}$, no se entiende en este caso como un retraimiento del individuo tras el asunto, sino como la renuncia, que necesita ser interpretada, de la propia individualidad en beneficio de la del otro: Sócrates.

Es un hecho que la interpretación de la relación socrático-platónica, más allá de las relaciones biográficas, también implica una determinada postura frente a la obra platónica. Nietzsche ha abordado la relación entre ambos filósofos de un modo muy variado, y dentro de estas reflexiones también se ha percatado de las opciones más inusuales. Si consideramos todo el espectro de posicionamientos frente a ambos atenienses, se hace evidente que el sondear su relación desconcertante posibilitó enormemente a Nietzsche una libertad de movimiento mayor en cuanto a la posibilidad de comprensión de sus filosofías. Los niveles de la reflexión sobre este sondeo se perfilarán a continuación.

En la presentación estética de El nacimiento de la tragedia se discute la constelación platónico-socrática desde la perspectiva del arte. En particular, el escepticismo provocativo del Sócrates estilizado como primer «hombre teórico» frente al paradigma estético de su tiempo, sobre todo con respecto a la tragedia clásica y a Eurípides, inicia así en la perspectiva predominante la conversión del dotado joven trágico Platón. Nietzsche recupera una tradición antigua, según la cual Platón, tras su primer enfrentamiento con Sócrates, quemó todas sus tragedias y las convirtió en filosofía, para contrastar el pathos de los héroes de escena de la tragedia con el logos de Sócrates, el «héroe dialéctico». Desde una perspectiva procedimental biográfica e histórico-evolutiva, la vida y el pensamiento de Platón se pueden interpretar, y marginar a la vez, a partir del dominio fáctico de la existencia socrática. En El nacimiento de la tragedia Platón está presente, en particular, en los roles de víctima, alumno, trasmisor y exponente del individuo socrático de la historia mundial ${ }^{17}$.

Más interesante que las determinaciones de esta relación asimétrica son las implicaciones de la misma. Sócrates, el enemigo del arte, prescinde a la vez de la escritura; en la redacción previa de GT anota Nietzsche en 1869 lo siguiente: «Sócrates como 'el que no escribe': él no quiere comunicar nada, se limita sólo a hacer preguntas» ${ }^{18}$.

En el propio libro no sólo se da por hecho esta determinación, sino que también se extrae más allá de ella una consecuencia: que precisamente la falta de escritura del maestro dialéctico elocuente obliga a Platón a su forma artística dialéctica. El hecho de que Platón, según el pensamiento del joven Nietzsche, escribiera sus diálogos «bajo la influencia demoníaca de Sócrates» ${ }^{19}$, cambia de nuevo la constelación ya de por sí paradójica: el discípulo, constreñido a la es-

16. En la Apologia Platón deja que su Sócrates responda ante un tribunal y nombre contraejemplos ¿̇cargados de prestigio en vistas a? la acusación de corrupción de menores. Aunque el propio Platón está presente, Sócrates llama, en vez de a este, al ausente Adimanto, «cuyo hermano es este Platón». En el Fedón (59b) se menciona de nuevo a Platón sólo para hablar de su ausencia, por motivos de enfermedad, del lecho de muerte de Sócrates.

17. Sobre el concepto de arte y ciencia de Nietzsche en El nacimiento de la tragedia véase Enrico Müller, «'Aesthetische Lust' und 'dionysische Weisheit'. Nietzsches Deutung der griechischen Tragödie»: Nietzsche-Studien 31 (2002), 134-153.

18. FP I 66, 1[24].

19. NT, en Obras completas, vol. 5, Buenos Aires: Aguilar, 1967, p. 79. 
critura dialógica por el maestro que no escribe, es a la vez su producto estético: «Platón es una obra de arte socrática» ${ }^{20}$.

La relación entre ambos pensadores, orientada predominantemente desde un punto de vista biográfico, no ha posibilitado aun a Nietzsche a mantener el diálogo en el punto de mira como medio de la escritura filosófica. Los diálogos de Platón se describen partiendo de la premisa de que ambos pensadores odian el arte arraigado bajo la forma de un mal necesario. Como «figura literaria» de un Sócrates, «a quien solía interpretar en vida», Platón marca con el diálogo «el prototipo de una obra de arte nueva ${ }^{21}$. Este prototipo es ahora para Nietzsche «el prototipo de la novela», el arte dialéctico se observa como derivado frente a un hacerse-presente realmente estético. Como medio para la representación de la existencia socrática tiene solamente el estatus de ancilla de la filosofía dialéctica: en el diálogo «el pensamiento filosófico rebasa el arte y le obliga a enlazarse estrechamente al tronco de la dialéctica ${ }^{22}$.

En la obra aforística del joven Nietzsche se encuentra, por el contrario, una imagen socrática notablemente modificada ${ }^{23}$. Paralelamente, Platón experimenta una revalorización tanto en las dos partes de Humano, demasiado humano como en Aurora. Son estimables también los aforismos en los que está tematizado fuera del área de influencia socrática, y que tratan principalmente del Platón político y legislador filosófico ${ }^{24}$. Su independencia filosófica la adquiere mayoritariamente a través del alto precio de la dogmatización de los diálogos platónicos en relación con las teorías platónicas. La polémica parcial de Nietzsche con él parece ser entendida por su parte como una conversación mantenida por medio de aforismos. El interlocutor se limita, sin embargo, a la mera presentación de tesis y posiciones. La nueva sensibilidad de Nietzsche con respecto a Sócrates como individuo filosófico no se relaciona aquí todavía con consideraciones sobre la forma dialógica. Las reservas naturalistas de Nietzsche, según las cuales hay que interpretar el diálogo como la práctica conversacional figurativa, parece influir hasta la mitad de los años ochenta. Nietzsche en un principio ha entendido los diálogos platónicos, y por encima de estos la forma aforística, desde la perspectiva del contenido proposicional y del resultado del movimiento pensante.

Ante el trasfondo del concepto de interpretación, en cuyo centro se encuentra la hipótesis de una pluralidad de sentidos constitutivos de la voluntad de poder, comienza Nietzsche a reflejar en su obra tardía la libertad interpretativa

20. FP I 200, 8[13].

21. NT, p. 79. (N. de la T.)

22. V. Tejera, Nietzsche and Greek Thought, cit., p. 84, menciona que «Nietzsche no ha tenido en cuenta realmente la afirmación de Laercio (III. 48,55 ) de que el diálogo es la forma elegida por Platón ¿̇para usar? el establishment de sus propias creencias». Esto vale seguramente para El nacimiento de la tragedia.

23. Catherine Zuckert, en Postmodern Plato: Nietzsche, Heidegger, Gadamer, Strauss, Derrida, Chicago, 1996, vincula este resultado, no de forma injusta, con la filosofía aforística de Nietzsche en contraposición a su primera obra: «En este periodo intermedio donde Platón parece más poético que Nietzsche, Nietzsche [...] aparenta ser más científico que Sócrates» (p. 18).

24. Laurence Lampert, «Nietzsche and Plato", en Paul Bishop (ed.), Nietzsche and Antiquity: His Reaction and Response to the Classical Tradition, Rochester, 2004, pp. 205-219 despliega a raíz de una interpretación de aforismos escogidos de Más allá del bien y del mal una imagen nietzscheana esotérica de Platón, que ofrece preferentemente una visión del ateniense como legislador con mucho estilo. Lo original es la tesis de que el platonismo esté ya establecido estructuralmente en los diálogos platónicos. 
de Platón frente a sus protagonistas. El foco del predominio socrático entendido desde un modelo de desarrollo histórico biográfico frente a su «alumno» se amplía en una perspectiva, en la que la filosofía platónica se señala como una interpretación de la existencia socrática.

A esto le corresponde también un nuevo entendimiento de la forma del diálogo por Nietzsche. En lugar de la esquematización aristotélica de los diálogos como «discursos socráticos», compartida por él durante mucho tiempo, aparece ahora un saber acerca de la fuerza performativa y deíctica del diálogo. En la nueva perspectiva adquirida se tergiversan también, lógicamente, las relaciones interpersonales - a favor de Platón y en contra de su «maestro»- A partir de ahora ensaya la idea de que Sócrates podría representar un tipo consecuente, pero filosóficamente estéril. Un moralista orientado hacia su filosofía de la vida, que a través de la estilización y de la dramaturgia de Platón puede optar por el rango de individuo excepcional y filosófico. Esto último se entiende como «el más audaz de todos los intérpretes; él, el que recogió de la calle a Sócrates entero, como el tema de una canción popular, para variarla hasta el infinito y hasta el imposible; es decir, que en ella puso sus propios disfraces y sus múltiples fases ${ }^{25}$.

Con respecto a los conceptos de «multiplicidad» (Vielfältigkeit) y de «máscara» (Maske), Nietzsche ha situado aquí, por primera vez, a Platón en el horizonte performativo de su propia estilística filosófica. Respecto al equivalente latino a tener en cuenta, persona, el plural de los conceptos tiene un significado eminente. Con él surge el esquema antitético del rol versus persona "auténtica», ser versus apariencia, significante versus significado. Habría que entender entonces al individuo como la «multiplicidad» de la personae, por consiguiente como la transición permanente de una «máscara» a otra. Puesto que en este sentido no se deja interrogar acerca de su peculiaridad, en la polémica con él lo limita a la propia individualidad.

Precisamente en esto podría consistir el sentido de la falta de ubicación de Sócrates en el corpus platónico. Platón ha inferido el habla de su protagonista de su individualidad, pero ha escenificado esta individualidad de tal forma, que se sustrae a cualquier acceso definitivo. En un fragmento póstumo de 1876, Nietzsche expone todavía esta práctica dramatúrgica como déficit conceptual o artístico. En los diálogos le parece Sócrates «sobrecargado con propiedades que nunca pueden estar juntas en una misma persona». El protagonista sumamente estilizado le valía «como caricatura corriente». De este modo, el mismo Platón no es lo «bastante dramaturgo para fijar la imagen de Sócrates, ni siquiera en un diálogo $»^{26}$.

$\mathrm{La}$ «caricatura corriente», que en su tiempo contraponía la imagen jenofóntica sobria de Sócrates a la realista, y por ello útil, la desveló Nietzsche en una época, en la que su estilo aforístico se había emancipado del modelo de los moralistas franceses y se había convertido en una forma nueva y propia de la escritura filosófica. En lugar de sentencias agudas y desenmascaradoras desde un punto de vista de observación neutral, aparece el aforismo puro de Nietzsche como mensaje reflejado múltiples veces con y carácter selectivo. La pretensión hermenéutica de defender una perspectiva determinada y bloqueada frente a la

25. JGB $\$ 190$, KSA V 111.

26. FP II 266, 18[47]. 
interpretación cede paso a un procedimiento que incluye al lector directamente en la reflexión más allá de la mera lectura reconstructora, y con ello precisa la movilización de su propia individualidad ${ }^{27}$. Las anotaciones nietzscheanas son concebidas interindividualmente, pero el lugar en el que el lector produce la comunicación ya no es fijo por su parte. Ese lugar viene marcado por gestos de indignación, defensa, irritación y aprobación no reflejada, junto con gestos de intervención personal involuntaria, de los cuales tampoco puede disponer un lector esforzado en la «objetividad».

Nietzsche se da cada vez más cuenta de que lo corriente de la representación platónica de Sócrates no es un diluirse de lo individual en la disparidad. Ve cómo Platón fusiona acertadamente la teoría y la reflexión individual. Y con ello ve también por primera vez las posibles reservas del individuo Platón, más allá de sus diálogos. Tras la presencia del dialéctico incomparablemente capaz de explicación y psicológicamente versado, Sócrates, el creador del diálogo, está presente y a la vez ausente. Mientras que Sócrates es presentado, al menos temporalmente, como grandeza interpretativa en el corpus platónico, por lo menos así se sugiere, el propio Platón permanece irreconocible y sólo se puede experimentar desde la distancia en relación con el acontecer del diálogo y con su protagonista. La apreciación más profunda de Nietzsche acerca de los diálogos platónicos es, a la vez, un alegato a favor de las almas múltiples y disfrazadas de Sócrates y Platón, quizás también la confesión de una «afinidad espiritual» filosófica $^{28}$. En un fragmento póstumo de 1885 confiesa, a la vista de su lectura de los diálogos, que sería una experiencia muy especial el poder observar a tal pensador verdadero. En la capacidad adquirida paulatinamente de poder «observar» esos diálogos también como escenarios teatrales, Nietzsche empieza a «descubrir que todo esto no es más que la fachada, y que él [el Sócrates platónico] en el fondo quiere otra cosa y la quiere de un modo muy audaz». El fragmento se cierra con las siguientes palabras:

Yo creo que la magia de Sócrates fue la siguiente: el tenía un alma y tras esta otra y tras esta otra. En la de más adelante se durmió Jenofonte, en la segunda

27. Reiner Wiehl, Nietzsches Antiplatonismus, cit., orienta el antiplatonismo nietzscheano hacia su nuevo concepto de la perspectiva. Wiehl comprende «la perspectividad de Nietzsche [...] desde la retórica y desde luego como una perspectividad sin perspectiva central» y con ello en contra de la tradición platónica de la perspectividad, la cual dice «que la verdad se muestra de forma múltiple, sin que con ello peligre la unidad de la verdad» (pp. 276 s.). El hecho de que Nietzsche ¿̇mientras tanto? no quisiera poetizar diálogos platónicos, porque "no era amigo de la dialéctica», es interpretado por Wiehl de una forma definitivamente demasiado poco profunda: «Quizás le faltara para ello la paciencia del pensar» (p. 285). En el pensamiento europeo hasta Nietzsche se ha preguntado casi exclusivamente por la unidad de las perspectivas abiertas por cada una de las personas en el diálogo. Precisamente por esto, en un principio, el diálogo no se presta a introducir en la filosofía, como alternativa a la metafísica, técnicas de comunicación reflejadas múltiples veces y un pensamiento perspectivista carente de perspectiva central.

28. Para Rosen, el "platonismo» de Nietzsche (op. cit., p. 13) es una «pregunta complicada, si la relación entre un Sócrates sobrio y la hermenéutica del enloquecimiento divino es análoga a la relación entre un Nietzsche sobrio y decadente y sus profecías [...]». Partiendo de esta base, a Rosen le parece «más correcto trazar una analogía entre Nietzsche y Platón que no entre Nietzsche y Sócrates». Rosen lleva esta analogía hasta los niveles de una producción estética aparente orientada en contra del mundo caótico y hasta una interpretación erótica del mundo — guiada por el deseo- y orientada en contra de la ontología. Simplemente se señala la analogización de la idea platónica con el concepto de perspectiva de Nietzsche en lugar de desarrollarla. 
Platón y en la tercera otra vez Platón, pero Platón con su segunda alma. El propio Platón es una persona con muchos trasfondos y fachadas ${ }^{29}$.

Hasta qué punto tuvo que haber comprendido Nietzsche esa nueva valoración de Platón, como también su cercanía, se demuestra en una carta que le escribió a Resa von Schirnhofer en la que dice lo siguiente sobre sí mismo: «Cada ermitaño tiene su cueva, precisamente en sí, y a veces detrás de la cueva tiene otra cueva y otra más - yo quería decir, que es difícil conocer a un ermitaño» ${ }^{30}$.

Nietzsche ha descrito aquí su soledad de un modo que no solo destaca el pathos de estar sólo. Lo otro de la soledad —el encuentro- sólo se hace posible allí donde la voluntad de comprender el interés en una comunidad de virtudes deja paso a la capacidad de «conocer a alguien» (Kennen-Lernen), o sea, al descubrimiento y al reconocimiento duradero de la reserva del otro. La «comprensión» nietzscheana de Platón parece agotarse en una polémica con el platonismo ortodoxo, porque creyó conocer a Platón ya antes de aprender a conocerlo y a reconocerlo: es complicado llegar a conocer a Platón.

\section{2. «ZARATUSTRA PLATONIZADO»: HACIA LA RELACIÓN ENTRE LOGOS Y PATHOS}

Así habló Zaratustra sigue siendo considerada todavía como la obra más discutible e inquietante de Nietzsche. A su autor le ha proporcionado la etiqueta de filósofo-poeta en un primer plano, y no sin una fundamentación plausible. Una etiqueta, que partiendo de un planteamiento similar, fue y es utilizada con frecuencia para Platón - y esto no ocurre por casualidad-. De hecho, el Zaratustra y los diálogos platónicos son comparables en cuatro aspectos: 1) Como textos están estructurados en parte narrativamente y en parte como reproducción de un discurso. Como escenificaciones interpretan un suceso sensorial, en un principio como un suceso argumentativo, y con ello predeterminan un contexto mundano y vital. 2) Las secuencias de discursos y acontecimientos de los diálogos y, en su caso, de la narración se ajustan a los protagonistas Sócrates y Zaratustra, dibujados carismáticamente. 3) En el carisma de sus protagonistas se encuentran presentes de forma característica Platón y Nietzsche, sin que esta presencia se manifieste. Con esto trascienden a sus protagonistas. 4) El discurso figurativo de Zaratustra y los mitos platónico-socráticos transforman el progreso discursivo del habla filosófica en un decir poético.

Si se quieren señalar los cuatro momentos mencionados como la manera de recubrir temas filosóficos con una figura literaria, diferenciando el «contenido» filosófico de la «forma» literaria, se podría poner en perspectiva el aspecto poéticoliterario meramente como derivado retórico de un querer-significar propiamente objetivo y se podría descuidar consecuentemente. Nietzsche, como es sabido, se cuestionó ya en Sobre verdad y mentira en sentido extramoral la diferencia entre forma y contenido con respecto a las exteriorizaciones lingüísticas, y extrajo el carácter retórico de toda denominación lingüística a partir de un origen estéticointuitivo. La pertinencia de prácticas discursivas vale desde este punto de partida

29. FP III 729, 34[66]. El fragmento es casi una caricatura opuesta a la valoración que hace en FP II, 18[47].

30. Nietzsche a Resa von Schirnhofer, 30 de marzo 1884, CO IV, 448, carta 500. 
como resultado de una esquematización que moviliza paulatinamente posibilidades de identificación a través de un sistema de convenciones que valen la pena. El Logos, como habla razonable, se constituye así primariamente a través de la exclusión y marginación de gestos retóricos primitivos. Sólo desde la perspectiva de una formación filosófica de conceptos se cierra el estatus impropio y originario de la retórica. Por último aparece como ornamento, es decir, se degrada en una forma lingüística disfrazada de sentido, o más bien regulada por el sentido ${ }^{31}$.

Tarde, aunque no demasiado, Nietzsche hizo valer los diálogos platónicos como medio de escritura filosófica y no como mero género literario ubicado en la mímesis. En otro lugar se ha mostrado cómo Platón, desde la perspectiva nietzscheana, por un lado elabora a partir de ello un problema que lo «define», y por otro lado, sin embargo, anula el tema así delimitado a través de una figuración dialógica, y lo hace visible en su carácter constitutivo: lo «representa» ${ }^{32}$. Platón consigue con esta interpretación una cercanía inmediata a la estructura performativa de Así habló Zaratustra. Nietzsche no buscó ni intuyó esa cercanía al escribir. La dimensión de la cercanía experimentada con respecto al filósofo dramático, Platón, se muestra en una confesión epistolar a Franz Overbeck. Bajo la influencia inmediata de la lectura de Gustav Teichmüller ${ }^{33}$, le confiesa Nietzsche a su amigo: «cada vez estoy más asombrado de lo poco que conozco a Platón, y de lo mucho que platoniza Zaratustra» ${ }^{34}$.

Esta identificación parcial no vale relativizarla ni sobrevalorarla. Nietzsche ha diagnosticado una platonización de su protagonista, pero no ha querido sacar una relación estructural entre su obra como totalidad y los diálogos platónicos, ni tampoco ha admitido una afinidad temática con el pensamiento de Platón ${ }^{35}$. Los paralelismos que resalta de forma insistente se limitan en su totalidad a la figura de Zaratustra y a la posibilidad de su figuración en la obra: Zaratustra y Sócrates actúan como sabios que enseñan, sin agotarse en su enseñanza ${ }^{36}$. Su actuación potente y efectiva polariza - ambos encuentran una aceptación apasionada, pero sin embargo se tropiezan con el rechazo y la ignorancia-. Como totalidades vivientes no son comprendidos por ninguno de sus numerosos adversarios. El abanico de sus posibilidades expresivas abarca desde el pathos apo-

31. En relación con esto, cf. Peter Gasser, Rhetorische Philosophie. Leseversuche zum metaphorischen Diskurs in Nietzsches «Also sprach Zaratustra», Bern/Berlin/Frankfurt a. M., 1992, en especial cap. X, «Rhetorik und Philosophie», pp. 203-218.

32. FP III 598, 26[357].

33. Gustav Teichmüller, Die wirkliche und die scheinbare Welt, Breslau, 1882. Cf. también Hans Nohl, «Eine historische Quelle zu Nietzsches Perspektivismus»: Zeitschrift für Philosophie und philosophische Kritik 149 (1913), 106-115.

34. Nietzsche a Overbeck, 22.10.1883, CO IV, 414, carta 469.

35. Lo mismo opina Mihailo Djuric, «Dichten und Denken im 'Zaratustra'», en J. Simon y M. Djuric (eds.), Kunst und Wissenschaft bei Nietzsche, Würzburg, 1986, pp. 75-100: «Cuando dijo que Zaratustra hablaba como Platón, Nietzsche sólo podía estar pensando notoriamente en una imitación con respecto a una correspondencia estructural, y no en el sentido de una repetición literal. No se puede hablar en ningún momento de la mera absorción del modelo platónico de filosofar, ya que 'Zaratustra' ni conoce ni reconoce el pensamiento discursivo [...]» (p. 97).

36. Hasta qué punto se convierten en paradójicas las enseñanzas de Zaratustra en la escenificación que Nietzsche hace de él, lo muestran Josef Simon, «Ein Text wie Nietzsches <Zaratustra>», y Werner Stegmaier, "Anti-Lehren. Szene und Lehre in Nietzsches 'Also sprach Zarathustra'», en Volker Gerhardt (ed.), Friedrich Nietzsche: Also sprach Zaratustra, Berlin, 2000, pp. 225-256 y pp. 191-224, respectivamente. 
calíptico hasta la polémica agresiva, desde secuencias discursivas hasta pasajes líricos. El discurso parabólico de Zaratustra y los mitos de Sócrates tientan las posibilidades metaforológicas del lenguaje deliberadamente. En la sobretensión de los potenciales metafóricos y en la creación de «metáforas absolutas» parece que quieren hacer visibles los abismos ocultos tras los motivos y eliminar y liberar al pensamiento de sus conceptos.

Zaratustra y Sócrates fracasan como maestros pero fascinan como seres vivientes. Ambas figuras están pensadas en su totalidad a partir de su unicidad, mejor dicho, a partir de la unicidad de su tarea: una autosuperación lograda, que transforma los valores y un autoconocimiento orientado a la explicación y preocupado por el alma.

Su unicidad se patho-logiza sobre esto de forma certera y así se incrementa aún más: Sócrates está expuesto a su daemon, es erotómano y en ocasiones se le describe bajo condiciones extremas sufriendo un entumecimiento paralizante durante horas o incluso noches. Zaratustra lucha contra sus pensamientos como contra la locura, los padece corporalmente. Puede dormir durante días, prescindir de comida y bebida, así como hablar con animales. Ambos se sienten apremiados por su tarea con respecto a las personas, personas a las que necesita en la búsqueda de lo común y, a la vez, a las que utilizan en el camino hacia su tarea trazada.

Lógicamente Zaratustra y Sócrates acaban en soledades dibujadas previamente y autoconfiguradas: este, en la soledad de su muerte designa su muerte como un acto ontológico y al mismo tiempo como una entrada en la vida verdadera y noetica; y el otro en la soledad del "gran mediodía» ${ }^{37}$.

Platón y Nietzsche, en la escenificación de dos personajes relativamente exaltados, han individualizado la dramatización de la vida y han señalado al mismo tiempo a la propia filosofía como transfiguración de un proyecto de vida ejemplar. Precisamente para conservar lo ejemplar de esa individualidad y poder expresarla adecuadamente, han dejado que sus dramas filosóficos ronden alrededor de la propia existencia. El concepto de individualidad guarda así una distancia con el de subjetividad. Zaratustra y Sócrates no pueden generar ningún mundo, porque ya se encuentran en él y se comportan con respecto a éste poetizando y queriendo, obrando y sufriendo. Nietzsche, que admite en Ecce homo en relación con sus obras anteriores, que escribía nolens volens sobre sí mismo, cuando escribía sobre otros, expone esta forma de ausencia presente como «sentimiento de la distancia», desde la cual se le hace presente su propia tarea. Una vez más se consulta a su gran predecesor para la explicación: «Así es como Platón se ha servido de Sócrates, como de una semiótica para Platón» ${ }^{38}$.

Así habló Zaratustra es en este sentido consecuencia de la experiencia. Zaratustra sería según esto una «semiótica» de Nietzsche al servicio de la tarea diseñada.

37. El fragmento póstumo demuestra que Nietzsche ha ponderado la muerte de su protagonista desde las premisas más variadas. El hecho de que Zaratustra no muera en la obra puede cobrar sentido a raíz de la conexión entre martirio y verdad, que Nietzsche ha labrado genealógicamente para Sócrates y Cristo. La muerte de Sócrates ha sido interpretada por Nietzsche — como ya ha mostrado— como una desindividualización acertada de su pensamiento; mientras que la existencia de Cristo, simbólica, subsistente sin valoración, sólo pudo ser malinterpretada como doctrina tras su crucifixión como víctima. La muerte de la figura de Zaratustra, que se sobrepasa de todos modos en cuanto a pathos, hubiera forzado de nuevo una interpretación instructiva de la obra.

38. EH, «Las intempestivas», 3, KSA VI 320. 
La filosofía de Nietzsche apunta a una imagen del hombre que prescinde de constataciones antropológicas y que expresa el exceso de posibilidades humanas más allá de estas determinaciones. La perspectiva de mantener abiertas estas determinaciones es el pensamiento de que el hombre sería el «animal aún no del todo fijado» ${ }^{39}$, y debería seguir siéndolo. Zaratustra, que por su parte simboliza esa indeterminación, «enseña» sobre todo en este sentido al «superhombre» el «sentido de la Tierra». Su «enseñanza» es de forma decisiva la explicación de ese exceso. Su talante y padecimientos, sus caminos que se dirigen a los hombres y se apartan de ellos son escenificaciones literarias de lo mismo. La dialogicidad de la obra platónica recurre por último de forma implícita a una idea del hombre, a lo común y conectado dentro de una estructura condicionante interindividual. El Zaratustra de Nietzsche, en contra de esto, sensibiliza con lo que separa a los seres humanos, su estructura interindividual es la de una «jerarquización». Los rangos no se exhiben como en una jerarquía, sino solamente a través de la sensación de diversidad, determinada por el «pathos de la distancia».

Así como las facultades de Zaratustra se sustraen cuando son identificadas, Así habló Zaratustra parece recomendar un medio de acceso a la comprensión (Verstehen). Escenifica la comprensión en sí ya no como ganancia de un significado determinado y limitado, sino como un movimiento dentro del exceso de significación. Como afirmación de ese movimiento remite a la capacidad de un correspondiente poder-comprender al otro. Lo otro en la comprensión remite a su vez a la persona como el otro - así Zaratustra puede delimitar el amor al prójimo, postulado bajo la exigencia de igualdad, a un «amor lejano» basado en la diferencia- ${ }^{40}$. La centralización del sentido realizada por el sujeto la ha descentralizado Nietzsche al no explicitar ya el movimiento de la comprensión en categorías del logos ni en conceptos, sino retrotrayéndose a un pathos. Precisamente en esto Zaratustra parece que ya no platoniza más. Su sensibilidad hacia la «accesibilidad del opuesto» es concebido como «el concepto de Dioniso en sí», frente a los procesos constitutivos de los diálogos platónicos que se reflejan ${ }^{41}$.

El pathos desprotegido de Así habló Zaratustra —que es fácilmente criticable ${ }^{42}$ - representa como forma de escritura filosófica un riesgo único incluso en la obra de Nietzsche. En Ecce homo, por su lado, se describe el lenguaje de Zaratustra como «lenguaje del ditirambo». Con respecto a la «canción de la noche» reproducida allí completamente, se considera precisamente por eso central para Nietzsche, porque de ella se desprende la vida y las «enseñanzas» de Zaratustra en su totalidad, a raíz del sufrimiento de la propia abundancia y del desgaste que va unido a ello como un don: «Nada igual se ha poetizado nunca, ni sentido, ni sufrido: así sufre un dios, un Dioniso» ${ }^{43}$.

Ante este trasfondo, el credo filosófico, que en la formulación nietzscheana previa se manifestaba como "platonismo invertido", adquiere un sentido preciso.

39. JGB $\$ 62$, KSA V 81.

40. Za I, «De la canción de la noche».

41. $\mathrm{EH}, \ll \mathrm{Za} », \mathbb{} 6$.

42. Claus Zittel, Das ästhetische Kalkül von Friedrich Nietzsches Also sprach Zaratustra, Würzburg, 2000, pp. 12 s. y 16 ss., se compromete en contra de la tendencia notablemente en aumento, dentro de las investigaciones sobre Nietzsche, a marginar filosóficamente a Zaratustra desde perspectivas cuestionables personales e influenciadas por el gusto apropiado de la época.

43. $\mathrm{EH}$, «a», $\mathbb{} 8$. 
En la mera contraposición del ser versus la apariencia, de idealidad versus realidad, de ontología versus fisiología no permite perfilar lo suficiente su pensamiento frente al «secreto de Platón y su naturaleza de esfinge» ${ }^{44}$. Platón permanece oculto de esta manera porque sus conceptos, diferenciaciones, jerarquizaciones y definiciones se escenifican bajo las condiciones específicas de la individualidad, la comunicatividad y la situacionalidad, y sólo a partir de esta puesta en escena adquieren relevancia filosófica en el diálogo. Las semánticas prolíficas de los diálogos han de ser interrogadas así acerca de la perspectiva doble de la constitución del sentido y la constitucionalidad del sentido. Nietzsche ha hecho esto por lo menos parcialmente, cuando cuestionaba al supuesto maestro Sócrates acerca de la «semiótica» platónica y aprendió a diferenciar entre sentido «definido» y «representado». Su antiplatonismo hay que enraizarlo, sin embargo, allí donde las oposiciones constituidas en los diálogos se independizan cada vez más con respecto al mundo de la vida, del que han surgido. La fuerza de las explicaciones gestadas por el Logos aumenta para Nietzsche de forma exponencial, cuando se margina en mero alogon un pathos que hace posible el pensamiento. La diferenciación lógico-interna de numerosos diálogos se realiza sobre el fundamento de una desvalorización sistemática de sus suplementos. Opiniones, experiencias, sufrimientos, voluptuosidades y deseos se nivelan sobre el estatus de un derivado epistemológico, en su carácter derivado han de ser explicitados y asegurados como pureza e incondicionalidad indispensable de las prácticas noéticas via negationis. Recordemos: Sócrates «inventó» la razón, según el diagnóstico de Crepúsculo de los ídolos, como "contratirano» frente a la tiranía existente de los instintos ${ }^{45}$. Percibió que su época estaba enferma, quiso ser médico y puso en marcha una transvaloración de los valores sin precedentes. Casi dos mil quinientos años más tarde se da una tiranía de la cultura y de la moral, cuyos valores quiere transvalorar Nietzsche como médico con la «contratiranía» de su propia filosofía.

Si se le concede a Nietzsche haber entendido la filosofía de Platón desde la tensión relacional entre pathos y logos, se hace mucho más comprensible su efecto duradero antiplatónico ${ }^{46}$. Una vez más, para poder cuestionar a un pensador emparentado con él, lo que se necesita es la cercanía. El pensamiento de Nietzsche también se pone en órbita en torno a la relación de fundamentación entre logos y pathos, pero en sentido contrario. Con los medios de la "genealogía», la «psicología», la «fisiología», el «inmoralismo» y el «perspectivismo» ha expresado radicalmente el condicionamiento del pensamiento por la moral, la cultura, el lenguaje, el cuerpo y la individualidad. La reflexión no se sacrifica entonces a un pathos «irracional», sino que se expone como una comprensión que abre aquellos contextos que se despojan de las apropiaciones reflexivas.

Volvamos con estos resultados de nuevo al principio: la «lucha contra Platón», según Nietzsche, "creó en Europa una maravillosa tensión de espíritu» —una tensión "como no existía aún en la Tierra»- Si esto es así, ya no puede haber para la filosofía una vuelta a Platón, pero tampoco cabe liberarse de él. Lo que queda es la fuerza que se concentra en el arco. Este arco - por seguir

44. JGB $\$ 28$, KSA V 47.

45. GD, «Das Problem des Sokrates».

46. Douglas Thomas, Reading Nietzsche Rhetorically, New York, 1999, entiende el pensamiento de Nietzsche en este sentido como aportación a una «deconstrucción de la filosofía de Platón» (pp. 1 ss.). 
con la metáfora de Nietzsche- se dejaría aflojar o incluso destensar. Pero con él también se puede «disparar a los objetivos más lejanos». El presupuesto para ello sería al menos un reconocimiento, una rectificación y un soporte de la tensionalidad del filosofar europeo: «Pero nosotros, [...] los buenos europeos y espíritus libres, muy libres - inosotros tenemos todavía toda la penosidad del espíritu y toda la tensión de su arco! Y quizás también la flecha, la tarea y ¿̇quién sabe?, incluso el blanco... ${ }^{47}$. 